\title{
Percieved Psychosocial Factors Affecting Uptake of Human Papilloma Virus (HPV) Vaccination among Female Civil Servants in Delta State, Nigeria
}

\author{
Beatrice M Ohaeri (RN- PhD, FWACN) ${ }^{1 *}$, Priscilla U. Ebunu (RN, Msc) ${ }^{2}$ \\ ${ }^{1}$ Department of Nursing, Faculty of Clinical Sciences, College of Medicine, University of Ibadan, Nigeria \\ ${ }^{2}$ State School of Nursing, Warri, Delta State Nigeria
}

\begin{tabular}{ll}
\hline DOI: $10.36348 /$ sjnhc.2020.v03i07.006 & | Received: 05.07 .2020 | Accepted: $21.07 .2020 \mid$ Published: 30.07 .2020 \\
*Corresponding author: Dr. Beatrice M. Ohaeri &
\end{tabular}

\section{Abstract}

Cervical cancer constitutes global health issue. Human Papilloma Virus Vaccine (HPV) has been associated with its prevention. Despite importance of the vaccine, studies have shown that diverse factors could impede its uptake. Therefore, this study assessed these perceived psychosocial barriers, as well as the uptake of HPV among Female Civil Servants in Delta State, Nigeria. Methods: The design was descriptive and cross-sectional. Multistage sampling technique was used to select 435 women, who consented. A structured questionnaire of 0.7 reliability coefficient was used to collect data at the Secretariat. Data were analyzed using frequency counts and the results were presented in tables and charts. Result: Mean age of participants was $32 \pm 6.7$ years. Many, (44.4\%) of them had adequate knowledge of the HPV and most (94.7\%), had not vaccinated their female adolescents. Cost $(54.5 \%)$ and inaccessibility $(51.3 \%)$ were projected as deterring factors. Psychosocial factors isolated were taboo and On the whole, $68.0 \%$ were enthusiastic about compliance with vaccination, later. Conclusion: Human Papilloma Vaccine is the primary prevention tool that could reduce the incidence of cervical cancer gobally. Subsidizing its cost by stakeholders and inclusion of National Immunization Programme could improve uptake. In addition, creating awareness about the vaccine, could improve knowledge, therefore ensuring that perceived barriers do not deter people from utilizing services. Active counselling by nurses / midwives will reduce fears, correct misconception and enhance uptake. Ultimately, there will be reduction in the global burden of cervical cancer.

Keywords: Barriers, Utilization, Human papilloma virus (HPV) vaccination.

Copyright @ 2020: This is an open-access article distributed under the terms of the Creative Commons Attribution license which permits unrestricted use, distribution, and reproduction in any medium for non-commercial use (NonCommercial, or CC-BY-NC) provided the original author and source are credited.

\section{INTRODUCTION}

Human papilloma virus (HPV) is one of the most common sexually transmitted infections in sexually active adolescents and young women and has been implicated as a cause of the majority of cases of cervical cancer, which is the second most common cancer in women in Nigeria. HPV is preventable with the use of HPV vaccine. It is said that about half of sexually active women will become infected during their life time. Exposure to Human Papilloma Virus (HPV), early age at sexual contact, multiple sex partners, multiparty, low screening uptake are risk factors of cervical cancer. Primary prevention involves HPV vaccination to protect pubescent girls from HPV infection. Studies have shown that early screening and vaccination will go a long way in the prevention of cervical cancer especially in Nigeria where the burden is high and is still increasing [1]. In Nigeria, uptake of
HPV vaccination has been demonstrated in different studies to be very low. This calls for concern on how to identify the barriers to HPV vaccination uptake and ways to offer solution.

Literatures conducted by some scholars in different countries have identified some factors that have been implicated to the low uptake of HPV vaccination. Psychosocial factors such as anxiety, fear of death, procrastination, poor health seeking behaviour, cost of vaccine, lack of social support, belief values, attitudes, cultural practices and constrains, lack of time, recession, misconception, economic status, religion of the women, fear of becoming positive, sources of reproductive health knowledge, access to health care, social influence of family members and other women have been identified $[2,3]$. Anecdotal notes show that these factors have not been proven to be the barriers for not accepting the HPV vaccination in Delta Sate. This 
research bridged that gap in knowledge and identified barriers associated with HPV and its uptake among female civil servants in Delta state.

There is a constant need to emphasize the benefit of HPV vaccination to Nigerian women [3]. Delta State is an oil producing state with relative better economy; HPV is scarcely available in hospitals, which could account to advanced cervical seen. Only few female adolescent had been vaccinated with HPV Hence, addressing this gap would be a welcome development. HPV vaccination which offers protection against HPV infection should therefore be encouraged as a primary preventive measure [4]. In a research done from London school of hygiene and tropical medicine with to access the economic benefit of vaccinating $80 \%$ of the world of 12 year old females against HPV, it was found that there was economic surplus if HPV vaccination was administered to preteens [5].

The benefit was from no treatment of precancerous lesions and cervical cancer besides saving more lives. This cost effectiveness also serves as impetus for wide spread adoption of HPV vaccination. A developing country like Nigeria has the potential to do the same and should be encouraged.

HPV is ubiquitous, as long as a child eventually has sex with another person; they are going to be exposed to HPV infection. It is better therefore to have been vaccinated against the HPV strains mostly associated with cervical cancer than not. The popular saying that prevention is better than cure should be applicable since Nigeria is not an exception to the increase in sexual permissiveness due to westernization. Furthermore, data from National population commission, Nigerian demographic and health survey [6] shows that the median age at first sexual intercourse in Nigeria is 17.7 years which almost corresponds to the peak age incident of HPV 18 to 25 years. This underscores the relevance of HPV vaccination acceptability in Nigerian communities [7]. In fact, with Delta state located at the coastal region with a lot of immigrant's employees, allowing for sexual permissiveness, the importance of HPV vaccination cannot be overemphasized. Therefore, a study to identify the barriers to the uptake of HPV vaccination in Delta state will be pertinent.

Delta state is said to be a micro Nigeria with numerous languages, cultural values, religions and beliefs that would affect cervical cancer screening and HPV vaccination. Therefore, this study reflects a wider opinion of Nigerians about cervical cancer screening and HPV vaccination. The female civil servants in Delta state ministries cut across all educational classes, cultural groups and different reproductive age group. Their opinion therefore represents the view of women generally.

\section{OBJECTIVES OF THE STUDY}

\section{The objectives of the study were to}

1. Describe the social-demographic characteristics of the participants

2. Assess knowledge and awareness of Human Papilloma Virus among female civil servants in Delta State.

3. Examine the uptake of HPV vaccination among female civil servants in Delta State.

4. Identify psychosocial factors influencing acceptability of HPV vaccination among female civil servants in Delta State.

\section{METHODOLOGY \\ Research Design}

The study is a cross- sectional, descriptive design, which utilized self-administered structured questionnaire to examine psychosocial factors influencing HPV vaccination acceptance and uptake.

\section{Target Population}

The target population was 14,953 female civil servants working in the Delta State secretariat were purposively selected based on the fact that there is concentration of female from diverse tribes working in different ministries in the secretariat. This gave the researcher access to the different social classes (low, middle and high social class).

Sampling Technique and sample: Multistage sampling technique was used. First, the Delta State secretariat was selected purposively; secondly, simple random sampling was used to select four (4) ministries (Ministry of Health, Ministry of Education, Ministry of Finance and Ministry of Works). A total of 435 willing women were purposively selected across the four ministries using the formula for calculating sample proportion:

$$
\begin{gathered}
n=z^{d} p q \\
d^{2}
\end{gathered}
$$

Where $\mathrm{z}=$ Taken as 1.96 which is the standard normal deviate. This corresponds to the $95 \%$ confidence levels. $\mathrm{P}=0.57$; the prevalence proportion, (Stocker, (1985), q = 1-p. thirdly, the participants were selected using systematic random sampling technique to ensure equal chance of being selected. Thus, the sampling frame containing the names of the women was obtained from the employment record in computer files of each selected ministry. The class interval and the selection starting point from the sample frames were determined randomly using the formula $(K=N / n)$. Where ' $K$ ' is the class interval, ' $\mathrm{N}$ ' is the total population in the four selected ministries and ' $\mathrm{n}$ ' is the sample size.

\section{Instrumentation}

A four -sectioned structured questionnaire designed based on the objectives of the study was used for data collection. Section A containing 8 items, elicited the socio demographic variables from the 
participants, while section $\mathrm{B}$ was designed to test knowledge of HPV. Section C assessed their uptake of HPV vaccination, while section $D$, was structured to identify possible psychosocial factors that may influence HPV vaccination. The content validity measure was ensured through the use of relevant literatures. The instrument was given to the expert in the field of Nursing, and supervisory team for thorough scrutiny. The instrument's reliability was determined by a test-retest approach, from centre not inclusive in the study. The internal consistency reliability was determined using Cronbach's $(r=0.7)$.

\section{Data Collection and Analysis}

Questionnaires administered to the female civil servants in the ministries were retrieved, checked for proper completion on collection from the participants by researcher and trained assistants. Data were coded and kept confidential and were analyzed using descriptive statistics. The findings were presented in tables and charts.

\section{Ethical Consideration}

The proposal was processed through the ethical Review Board of the Ministry of Health, Asaba, and Delta State with approval number HM/596/T/143. All participants gave informed consent prior to data collection and necessary permission was taken from the ministries. Respondents were informed that their information will be kept confidential and the researcher ensured the anonymity of the instrument.

\section{RESULTS}

Out of the 437 questionnaires given out, 435 were well filled and retrieve immediately after completion. Hence, the return rate was $99.5 \%$. The results are presented below.

Research question 1: What are the social-demographic characteristics of the participants?

Table-1: Social-demographic information of participants $(N=435)$

\begin{tabular}{|c|c|c|c|}
\hline Socio-demographic information & Frequency & Percent & Mean \\
\hline \multicolumn{4}{|l|}{ Age categories (Years) } \\
\hline 25 and Below & 94 & 21.6 & \\
\hline $26-35$ & 254 & 58.4 & \\
\hline $36-45$ & 69 & 15.9 & \\
\hline 46 and above & 18 & 4.1 & \\
\hline \multicolumn{4}{|l|}{ Mean Age : 32 years \pm 6.97 years } \\
\hline Teenagers & 6 & 1.4 & \\
\hline Young women & 320 & 73.6 & \\
\hline Elderly women & 109 & 25.1 & \\
\hline \multicolumn{4}{|l|}{ Highest level of education } \\
\hline Primary & 38 & 8.7 & \\
\hline Secondary & 112 & 25.7 & \\
\hline OND & 73 & 16.8 & \\
\hline HND/BSc & 197 & 45.3 & \\
\hline Postgraduate & 15 & 3.4 & \\
\hline \multicolumn{4}{|l|}{ Ministries } \\
\hline Education & 203 & 46.7 & \\
\hline Health & 96 & 22.1 & \\
\hline Finance & 70 & 16.1 & \\
\hline Works & 66 & 15.2 & \\
\hline \multicolumn{4}{|l|}{ Marital status } \\
\hline Single & 57 & 13.1 & \\
\hline Married & 370 & 85.1 & \\
\hline Divorced & 4 & 0.9 & \\
\hline Separate & 4 & 0.9 & \\
\hline \multicolumn{4}{|l|}{ Religion } \\
\hline Islam & 47 & 10.8 & \\
\hline Christianity & 370 & 85.1 & \\
\hline Traditional & 3 & 0.7 & \\
\hline No specific religion & 15 & 3.4 & \\
\hline \multicolumn{4}{|l|}{ Ethnicity } \\
\hline Urhobo & 174 & 40.0 & \\
\hline Itsekiri & 17 & 3.9 & \\
\hline Ijaw & 22 & 5.1 & \\
\hline Other ethnic groups & 222 & 51.0 & \\
\hline
\end{tabular}




\begin{tabular}{|l|r|r|l|}
\hline Parity of women & & & \\
\hline Nulliparous women & 151 & 34.7 & \\
\hline Primiparous women & 113 & 26.0 & \\
\hline Multiparous women & 159 & 36.6 & \\
\hline Grand multiparous women & 12 & 2.8 & \\
\hline Estimated monthly income & & & \\
\hline Below $18000(\leq \$ 50)$ & 118 & 27.1 & \\
\hline $18000-37000(\leq \$ 100)$ & 196 & 45.1 & \\
\hline $38000-57000(\leq \$ 150)$ & 64 & 11.0 & \\
\hline Above 57000 $(>\$ 150)$ & 9 & 14.7 & \\
\hline Income not specified & & 2.1 & \\
\hline
\end{tabular}

Table 1 present the participants' sociodemographic information. Majority $320(73.6 \%)$ were young women, married $370(85.1 \%)$, College graduates $197(45.3 \%)$ and mainly Christians 370 (85.1\%).
Besides, $159(36.6 \%)$ were multiparous, some nulliparous, women while grand multiparous where12 $(2.8 \%)$, were the least. Many 196 (45.1\%), earned less than $\$ 100$, while $64(14.7 \%)$ earned above $\$ 150$.

Table-2: presents the summary of the levels of knowledge of HPV vaccine among the women. A total of 55.6\% had inadequate knowledge while $44.4 \%$ had adequate knowledge of the HPV vaccine

\begin{tabular}{|l|r|r|}
\hline Levels of knowledge & Frequency & Percent \\
\hline Inadequate knowledge & 242 & 55.6 \\
\hline Adequate knowledge & 193 & 44.4 \\
\hline Total & $\mathbf{4 3 5}$ & $\mathbf{1 0 0 . 0}$ \\
\hline
\end{tabular}

Table 3: presents the number of times the participants had taken their teenage girls for HPV vaccine. Most of the participants 412 (94.7\%) had never vaccinated their teenage girls with HPV.

Table-3: Numbers of times HPV was given to participants' teenage girls

\begin{tabular}{|l|r|r|}
\hline Numbers of times HPV was given to their teenager & Frequency & Percent \\
\hline One & 13 & 3.0 \\
\hline Two & 4 & 0.9 \\
\hline Three & 6 & 1.4 \\
\hline Never vaccinated anyone & 412 & 94.7 \\
\hline Total & $\mathbf{4 3 5}$ & $\mathbf{1 0 0 . 0}$ \\
\hline
\end{tabular}

Table-4: Participants' future decision for utilization of HPV vaccination for their teenage girls was assessed. Majority $296(68 \%)$ are willing to take their girls for HPV, at a later date

Table-4: Participants' future decision for utilization of HPV vaccination for teenage girls

\begin{tabular}{|l|r|r|}
\hline Future decision for utilization of HPV vaccine & Frequency & Percent \\
\hline Willing to take their teenage girls for HPV vaccination & 296 & 68.0 \\
\hline Unwilling to take their teenage girls for HPV vaccine & 80 & 18.4 \\
\hline Not sure to take their teenage girls for HPV vaccine & 36 & 8.3 \\
\hline Never vaccinate teenage girls with HPV vaccine & 23 & 5.3 \\
\hline Total & $\mathbf{4 3 5}$ & $\mathbf{1 0 0 . 0}$ \\
\hline
\end{tabular}

Table 5: The psychological factors influencing uptake of HPV vaccination among the participants are presented. Unaffordable cost of the vaccine 237 (54.5\%), inaccessibility to the HPV vaccine center 253 $(51.3 \%)$ and unavailability of the HPV vaccine as factors that influence the uptake of HPV vaccination. Other purely psychological factors like fears, family supports, were equally assessed; they didn't appear to have much influence. 
Table-5: Psycho-social factors influencing acceptance of HPV vaccine

\begin{tabular}{|l|c|c|c|c|}
\hline \multicolumn{1}{|c|}{ Possible psycho-social factors } & \multicolumn{2}{|c|}{ Yes } & \multicolumn{2}{c|}{ No } \\
\cline { 2 - 5 } & $\mathbf{N}$ & $\mathbf{( \% )}$ & $\mathbf{N}$ & $\mathbf{( \% )}$ \\
\hline Unaffordable cost of the HPV vaccine & 237 & $(54.5)$ & 198 & $(45.5)$ \\
\hline Fear of discomfort or pain from HPV injection & 169 & $(38.9)$ & 266 & $(61.1)$ \\
\hline Fear of adverse effect(s) of HPV vaccine & 162 & $(37.2)$ & 274 & $(62.8)$ \\
\hline Unavailability of HPV vaccine & 216 & $(49.7)$ & 219 & $(50.3)$ \\
\hline Inaccessibility to the HPV vaccine centres & 223 & $(51.3)$ & 212 & $(48.7)$ \\
\hline Fear of lack of privacy and lack confidentiality during of HPV vaccine & 142 & $(32.6)$ & 293 & $(67.4)$ \\
\hline Lack of support from my spouse (husband) for HPV vaccine & 118 & $(27.1)$ & 317 & $(72.9)$ \\
\hline Lack of support from my mother-in-law or husband relatives & 88 & $(20.2)$ & 347 & $(79.8)$ \\
\hline I am being discouraged by my friends or colleagues & 75 & $(17.2)$ & 360 & $(82.8)$ \\
\hline HPV vaccine is forbidden by religion & 54 & $(12.4)$ & 381 & $(87.6)$ \\
\hline Family/community taboo & 47 & $(10.8)$ & 388 & $(89.2)$ \\
\hline schedule/nature of work & 76 & $(17.5)$ & 359 & $(82.5)$ \\
\hline Discouraging attitude of health workers & 107 & $(24.6)$ & 328 & $(75.4)$ \\
\hline Lack of belief in HPV vaccine as a means of prevention & 103 & $(23.7)$ & 332 & $(76.3)$ \\
\hline Fear being labeled or stigmatized as a promiscuous lady & 120 & $(27.6)$ & 315 & $(72.4)$ \\
\hline
\end{tabular}

This result is equally seen in the assessment of the association between these factors and uptake of the vaccine. No significant association between presence of psychosocial factors (anxiety, religious belief, cost of the vaccine, fear of contracting the disease, availability of the vaccine and facilities, parental attitudes, cultural practices, etc) and acceptance of HPV vaccination $(\mathrm{p}<0.05)$. However, in assessing the variables one by one, revealed cultural taboos and lack of belief in HPV vaccine were significantly associated as a means of uptake of of HPV among the women. This implies that greater percentage of women who were restrained by cultural taboos and lack of belief did not allow their girls to take HPV vaccine compared to women who had no such restraints.

Table-6: Association between psycho-social factors and uptake of HPV
\begin{tabular}{|l|c|c|c|c|c|c|}
\hline Psychosocial factors & Uptake of HPV & $\boldsymbol{\chi 2}^{\mathbf{2}}$ & Df & P-v & Remark \\
\hline Unaffordable cost & Yes & No & & & & \\
\hline No & 11 & 181 & & & & \\
\hline & 47.8 & 43.9 & 0.134 & 1 & 0.83 & NS \\
\hline Yes & 12 & 231 & & & & \\
\hline & 52.2 & 56.1 & & & & \\
\hline
\end{tabular}

\begin{tabular}{|c|c|c|c|c|c|c|}
\hline & \multicolumn{2}{|c|}{ Uptake of HPV } & & & & \\
\hline Fear of discomfort/pain/unsafe procedure & Yes & No & & & & \\
\hline \multirow{2}{*}{ No } & 12 & 206 & & & & \\
\hline & 52.2 & 50.0 & 0.041 & 1 & 0.83 & NS \\
\hline \multirow[t]{3}{*}{ Yes } & 11 & 206 & & & & \\
\hline & 47.8 & 50.0 & & & & \\
\hline & \multicolumn{2}{|c|}{ Uptake of HPV } & & & & \\
\hline Fear of adverse effect(s) of pap smear & Yes & No & & & & \\
\hline \multirow{2}{*}{ No } & 12 & 228 & & & & \\
\hline & 52.2 & 55.3 & 0.088 & 1 & 0.08 & $\mathrm{NS}$ \\
\hline \multirow[t]{3}{*}{ Yes } & 11 & 184 & & & & \\
\hline & 47.8 & 44.7 & & & & \\
\hline & \multicolumn{2}{|c|}{ Uptake of HPV } & & & & \\
\hline Inaccessibility to the cervical screening service & Yes & No & & & & \\
\hline \multirow[t]{2}{*}{ No } & 13 & 170 & & & & \\
\hline & 56.5 & 41.3 & 2.081 & 1 & 0.19 & NS \\
\hline \multirow[t]{3}{*}{ Yes } & 10 & 242 & & & & \\
\hline & 43.5 & 58.7 & & & & \\
\hline & \multicolumn{2}{|c|}{ Uptake of HPV } & & & & \\
\hline Inaccessibility to the cervical screening facilities & Yes & No & & & & \\
\hline \multirow[t]{2}{*}{ No } & 12 & 170 & & & & \\
\hline & 52.2 & 41.3 & 1.066 & 1 & 0.39 & NS \\
\hline \multirow[t]{3}{*}{ Yes } & 11 & 242 & & & & \\
\hline & 47.8 & 58.7 & & & & \\
\hline & \multicolumn{2}{|c|}{ Uptake of HPV } & & & & \\
\hline Fear of lack of privacy and lack confidentiality & Yes & No & & & & \\
\hline No & 15 & 241 & & & & \\
\hline
\end{tabular}




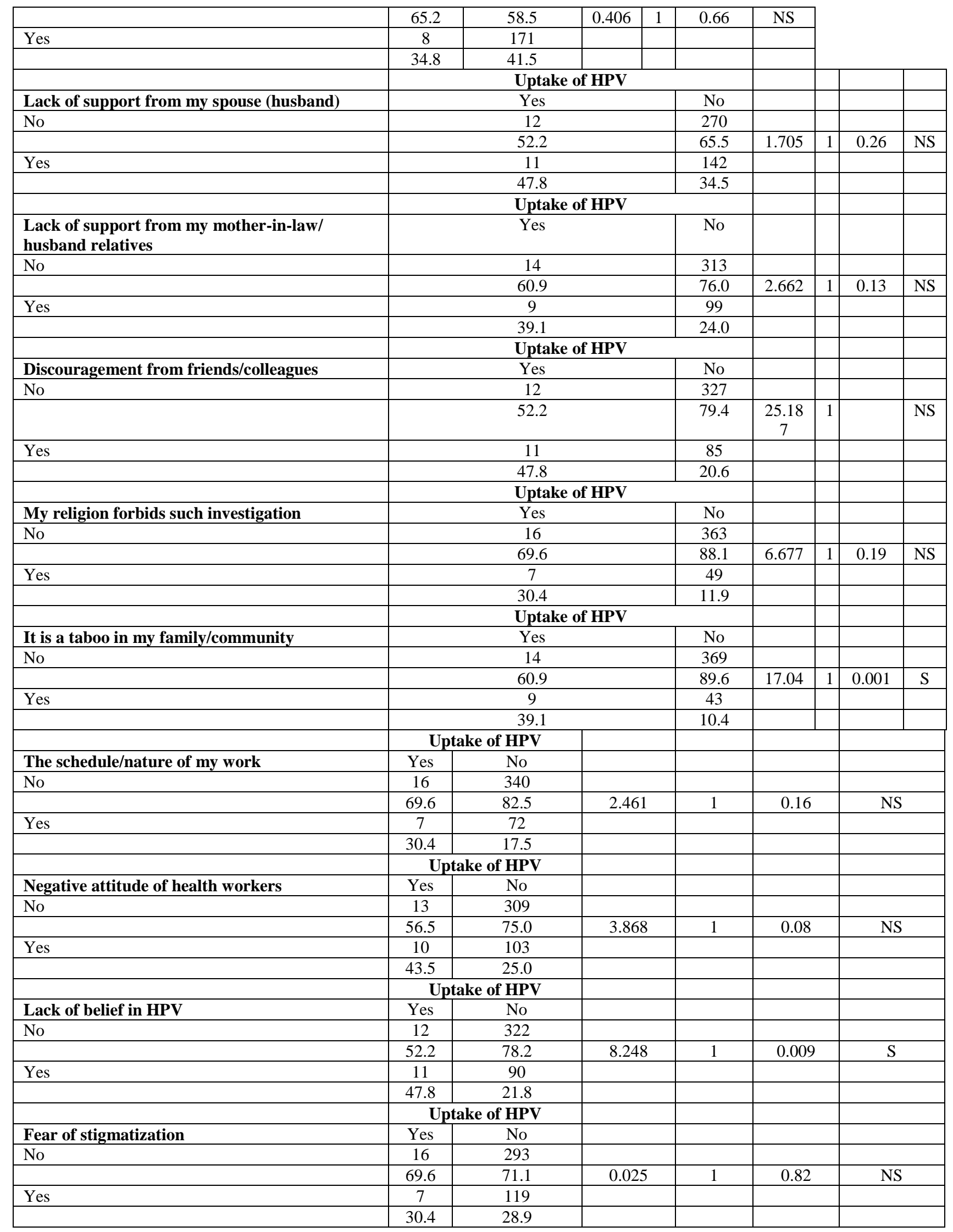


Table-7: Relative contributions of predictor variables to uptake of HPV services

\begin{tabular}{|l|c|c|c|c|c|}
\hline Model & \multicolumn{2}{|c|}{$\begin{array}{c}\text { Unstandardized } \\
\text { Coefficients }\end{array}$} & $\begin{array}{c}\text { Standardized } \\
\text { Coefficients }\end{array}$ & T & Sig. \\
\hline A & B & Std. Error & Beta & & \\
\hline (Constant) & 1.913 & 0.149 & & 12.8 & 0.000 \\
\hline Age & 0.001 & 0.002 & 0.043 & 0.743 & 0.458 \\
\hline Highest educational qualification & 0.004 & 0.024 & 0.007 & 0.144 & 0.885 \\
\hline Marital status & 0.079 & 0.033 & 0.127 & 2.444 & 0.015 \\
\hline Religion & 0.022 & 0.022 & 0.050 & 1.034 & 0.302 \\
\hline Number of Child/Children & -0.016 & 0.009 & -0.100 & -1.78 & 0.076 \\
\hline Estimated monthly income & 0.004 & 0.011 & 0.021 & 0.41 & 0.682 \\
\hline Awareness of cervical cancer & -0.027 & 0.024 & -0.060 & -1.12 & 0.263 \\
\hline Knowledge of cervical cancer & 0.003 & 0.006 & 0.029 & 0.535 & 0.593 \\
\hline Perceived Susceptibility & -0.002 & 0.001 & -0.072 & -1.45 & 0.147 \\
\hline Unaffordable cost of the HPV vaccine & -0.024 & 0.026 & -0.053 & -0.91 & 0.366 \\
\hline Inaccessibility to the HPV vaccine service & -0.010 & 0.026 & -0.023 & -0.4 & 0.691 \\
\hline Lack of spousal support for HPV vaccine & 0.006 & 0.029 & 0.013 & 0.224 & 0.823 \\
\hline Attitude of health workers & -0.004 & 0.029 & -0.008 & -0.14 & 0.892 \\
\hline Psychosocial factors & -0.006 & 0.004 & -0.108 & -1.58 & 0.116 \\
\hline
\end{tabular}

a. Dependent variable: Uptake of HPV services.

b. Predictor variables: Age, Marital status, Religion.........., Psychological factors.

Assessing the relative contribution of the predictor variables on the uptake of cervical screening, the F-ratio in the ANOVA table examined the degree to which the relationship between them was linear. The only predictor variables that significantly predicted the dependent variable was marital status $(\mathrm{t}=2.444, \mathrm{p}<$ $0.05)$.

In addition a composite contribution of predictor variables to the dependent variable was equally assessed. The total variance of predictor variables was $\mathrm{R}^{2}=0.046$. It can therefore be deduced that $4.6 \%$ of the total variance in utilization of cervical cancer screening was accounted for by the predictor variables, leaving the $96.4 \%$ to chance and residual.

\section{DISCUSSION OF FINDINGS}

A large proportion of the participants, $73.6 \%$ were young women with a mean age of $32 \pm 6.97$ years is in line with other studies, as they were mainly mothers with teenage children. Therefore, it is important to advice these women to utilize HPV vaccination services available for their female teenagers.

The inadequate knowledge level seen in majority of the participants had been noted. Mobolanle, et al. [8], in a community based descriptive study found that awareness and uptake of HPV vaccine was very low too. Although they also reported that awareness and HPV vaccine uptake was increased with increasing educational level, ours seem to differ as educational level had no association with utilization. This could be attributed to the poor awareness. It could also be related to poor financial status of the participants as majority earned less than $\$ 100$ US dollars monthly. The low utilization of HPV for the teenagers is also in line with previous studies. Olugbenga, et al. [9], stated the factors affecting uptake identified by their study, which includes cost of the HPV. In line our own observation, most participants also claimed that cost of the vaccine was an important variable as $54.5 \%$ believed that the vaccine was too expensive, and thus will make them not to utilize it. Cost of HPV vaccination could be a real limiting factor. In a region where poverty is high and many other pressing issues competing for the scarce resource, out of pocket payment for non-emergency health services like HPV vaccination could be a major barrier to women [1]. It is suggested that HPV vaccine should be subsidized by stake holders and it should be added to national health insurance scheme (NHIS).

Only a very few mothers, $18.4 \%$, were willing to screen their teenage daughters. This stems from their background understanding of what cervical cancer is, and the need for vaccination of their daughters before the onset of sexual activities, as the onset of the disease is usually 18 years. A study carried out by Low, et al. [10], reported that parental attitudes are keys to understanding HPV vaccination outcomes. Parents demonstrated a poor understanding of HPV, reported little or no knowledge of HPV, and were unaware of the associations of HPV with Pap testing and cervical cancer. However, parents reported high levels of interest in HPV vaccination for their adolescents at a later date [11], which is line with the observation in this study. A study conducted by Slomovitz and colleagues [12] that demonstrated high uptake of HPV vaccine among participants and their children is in conflict with findings from this study, where $94.7 \%$ of the participants had never vaccinated their teenagers. Balogun, Odukoya, Oyediran, Ujomu, 2012, submitted that mothers felt that HPV infection does not pose a great risk to their children; mothers lacked knowledge of the vaccine, thought their children were too young to 
receive the vaccine, were unsure of the long-term effects from the vaccine, and had low acceptability to cervical cancer screening and HPV vaccination. This also goes in line with the findings of this as lack of belief and family taboo had significant relationship with uptake.

It is important to note that although psychosocial factors did not influence the uptake or acceptance of HPV vaccine significantly, there were varying degrees of influences evidence in descriptive analyses. A small proportion of the respondents $(12.4 \%)$ believe that their religion has a great influence on utilization of HPV Vaccine This is in contrast with Natal, 2011, who found out Israel mothers were influenced by religion as a factor impeding vaccination for their daughters. Modibo, Dareng, Bamisaye, Agba, Adewole, et al. [13] in their study, also showed that religious and cultural factors could have significant impact on health seeking behaviors and should not be underestimated. Religious practices and teachings may influence beliefs about the acceptability of the HPV vaccination. Some believe in abstaining from sex until marriage and parents with such belief may perceive vaccinating their daughters as unnecessary since they are morally supposed to abstain from sex until marriage. As such they view HPV vaccination as morally inappropriate and attempt to increase sexual permissiveness [14, 2]. Molande, Ifeoma\& Beatrice [15] found that ethnicity and religion has no statistically significant influence on HPV vaccine acceptability. The study population was majorly Christians and the study was carried out in the Southern part of Nigeria. Similarly, Balogun 2012 showed that Christians in Nigeria, especially the Southern part have not shown any negative attitude towards any vaccines offered in Nigeria. This impart of religion that in turn influences the psychosocial attitude towards HPV vaccination was not significantly felt in their study population. This finding therefore agrees with result from this study, which has only a few participants agreeing to the fact that religion has a significant influence on acceptability of HPV vaccination.

Other researchers like [16], and [17] found that psychosocial issues such as shame of the disease, stigmatization and fatalistic view of a positive result were the main reasons why women will decline HPV vaccination. All these findings agree with the result from this study, asserting shame as one of the psychosocial factors impeding utilization of HPV vaccination. A good proportion of the respondents, $38.9 \%$ reported fear of discomfort or pain from HPV injection, while $37.2 \%$ of the respondents reported fear of adverse effect(s) of HPV vaccine as barriers to uptake of screening services and vaccination. Also, Ndikom \& Ofi [1]; Ngugi, Bagatt, Muigai [18] in their studies reported that fear was a factor that led to poor uptake of HPV vaccination. Literatures from these studies have been able to highlight the need to allay women's fear of vaccination.

Other noted psycho-social factors in this study: discouragement from friends/colleagues, religious belief, cultural taboos, schedules/nature of work and lack of belief in the HPV vaccination which negatively influenced their utilization and uptake, respectively is a serious health concerns. Therefore, intervention focusing on disabusing the mind of the women in order to improve the acceptance and uptake of HPV vaccine as a preventive measure is going to be a panacea to the unacceptable increase in cervical cancer morbidity and mortality among the women. Therefore, future studies to solve the identified psycho-social problems reported in this study are recommended.

It's also worthy of note, that the only factor that relatively predicted uptake was marital status. This could be explained by the fact that spousal support is very important variable to promote utilization of HPV. In a culture that prohibits women from taking vital decisions concerning their health without the husband's support, it could act as barrier. However, the total prediction by all the independent variables was $4.6 \%$. This leaves a lot to be desired as $93.4 \%$, is still not accounted for in this study. There is suggestive of the fact there are other variables that needs to explore. A future longitudinal study with wider coverage is being advocated.

\section{RECOMMENDATIONS}

HPV vaccine should be made available at the primary health care centers, to ensure accessibility and availability at the grass root.

The cost of HPV vaccine should be subsidized by the government to ensure that cost does not impede uptake of HPV vaccine.

\section{Implication to Nursing}

Nurses are the largest population of health care workers in the health care sector, and must therefore, try as much as possible to sensitize patients about HPV vaccination available.

Enhancing the counselling skills of nurses/ midwives will go long in reducing fears associated with HPV vaccine utilization and uptake among mothers

\section{CONCLUSION}

HPV vaccination is the primary prevention at ensuring reduction in the incidence of cervical cancer in the society to the barest minimum. Creating awareness about HPV vaccine could be a means to help tackle the lack of knowledge, thereby increasing knowledge and possible utilization. In addition, subsidization will go a long way in lessening the financial burden, as well as increase utilization. Subsequently global burden of 
cervical cancer will be reduced, with a consequent reduction in mortality.

\section{REFERENCES}

1. Ndikom, C. M., \& Ofi, B. A. (2012). Awareness, perception and factors affecting utilization of cervical cancer screening services among women in Ibadan, Nigeria: a qualitative study. Reproductive health, 9(1), 11.

2. Teng, F. F., Mitchell, S. M., Sekikubo, M., Biryabarema, C., Byamugisha, J. K., Steinberg, M., \& Ogilvie, G. S. (2014). Understanding the role of embarrassment in gynaecological screening: a qualitative study from the ASPIRE cervical cancer screening project in Uganda. BMJ open, 4(4).

3. Ajah, L. O., Iyoke, C. A., Ezeonu, P. O., Ugwu, G. O., Onoh, R. C., \& Ibo, C. C. (2015). Association between knowledge of cervical cancer/screening and attitude of teachers to immunization of adolescent girls with human papilloma virus vaccine in Abakaliki, Nigeria. American Journal of Cancer Prevention, 3(1), 8-12.

4. Nwobodo, H., \& Ba-Break, M. (2015). Analysis of the determinants of low cervical cancer screening uptake among Nigerian women. Journal of public health in Africa, 6(2).

5. World Health Organization. (2014). Global status report on noncommunicable diseases 2014 (No. WHO/NMH/NVI/15.1). World Health Organization.

6. Akanbi, O. A., Iyanda, A., Osundare, F., \& Opaleye, O. O. (2015). Perceptions of nigerian women about human papilloma virus, cervical cancer, and HPV Vaccine. Scientifica, 2015.

7. Chigbu, C. O., \& Aniebue, U. (2011). Why southeastern Nigerian women who are aware of cervical cancer screening do not go for cervical cancer screening. International Journal of Gynecologic Cancer, 21(7).

8. Taiwo, A., Micheal, A., Wasiu, A., Mobolanle, O., \& Akin, L. (2013). Assessment of cleft lip and palate surgeries at a nigerian teaching hospital. International Journal of Oral and Maxillofacial Surgery, 42(10), 1204.

9. Chidyaonga-Maseko, F., Chirwa, M. L., \& Muula, A. S. (2015). Underutilization of cervical cancer prevention services in low and middle income countries: a review of contributing factors. Pan African medical journal, 21(1).
10. Low, E. L., Simon, A. E., Lyons, J., RomneyAlexander, D., \& Waller, J. (2012). What do British women know about cervical cancer symptoms and risk factors?. European Journal of Cancer, 48(16), 3001-3008.

11. DiAngi, Y. T., Panozzo, C. A., Ramogola-Masire, D., Steenhoff, A. P., \& Brewer, N. T. (2011). A cross-sectional study of HPV vaccine acceptability in Gaborone, Botswana. PloS one, 6(10), e25481.

12. Brabin, L., Roberts, S. A., Farzaneh, F., \& Kitchener, H. C. (2006). Future acceptance of adolescent human papillomavirus vaccination: a survey of parental attitudes. Vaccine, 24(16), 30873094.

13. Modibbo, F. I., Dareng, E., Bamisaye, P., JedyAgba, E., Adewole, A., Oyeneyin, L., ... \& Adebamowo, C. (2016). Qualitative study of barriers to cervical cancer screening among Nigerian women. BMJ open, 6(1).

14. Wamai, R. G., Ayissi, C. A., Oduwo, G. O., Perlman, S., Welty, E., Manga, S., \& Ogembo, J. G. (2012). Assessing the effectiveness of a community-based sensitization strategy in creating awareness about HPV, cervical cancer and HPV vaccine among parents in North West Cameroon. Journal of community health,37(5), 917-926.

15. Marlow, L. A., Zimet, G. D., McCaffery, K. J., Ostini, R., \& Waller, J. (2013). Knowledge of human papillomavirus (HPV) and HPV vaccination: an international comparison. Vaccine, 31(5), 763-769.

16. Luppi, P. H., \& Fort, P. (2011). What are the mechanisms activating the sleep-active neurons located in the preoptic area?. Sleep and Biological Rhythms, 9(1), 59-64.

17. Morhason- Bello, I. O., Wallis, S., Adedokun, B. O., \& Adewole, I. F. (2015). Willingness of reproductive- aged women in a Nigerian community to accept human papillomavirus vaccination for their children. Journal of Obstetrics and Gynaecology research, 41(10), 1621-1629.

18. De Sanjosé, S., Serrano, B., Castellsagué, X., Brotons, M., Muñoz, J., Bruni, L., \& Bosch, F. (2012). Human papillomavirus (HPV) and related cancers in the Global Alliance for Vaccines and Immunization (GAVI) countries. A WHO/ICO HPV Information Centre Report. Vaccine, 30(Suppl 4), D1-83. 